\title{
INVESTIGATING THE PROBLEMS ENCOUNTERED BY EFL STUDENTS IN TRANSLATING ENGLISH IDIOMS INTO ARABIC OR VICE VERSA
}

\author{
Abdelazim Mabrook Abdalbein Mabrook \\ azima7211@hotmail.com \\ Onaizah Colleges, K.S.A
}

\begin{abstract}
Translating idioms is an indispensable part of human life which involves language, thought and action. This study aims to investigate the problems encountered by EFL students in translating English idioms into Arabic or vice versa and set up some solutions. The study hypothesizes that university students are unable to translate idioms from English to Arabic and vice versa. To fulfil this study, the descriptive-analytic method is used and to be followed. A questionnaire is used as data collection instruments. The sample of the study consisted of (20) students from the third and fourth school year at Onaizah Colleges, Qassim, K.S.A. The study found that the differences in the average of the consensus are in favour of the variables that translating idioms is a problematic area for Saudi EFL students. Likewise, EFL students are confused in translating idioms from English to Arabic and vice versa due to poor vocabulary and fixed idiomatic expressions. Moreover, EFL students translate the idioms from English to Arabic and vice versa literally. The study recommends that EFL students should be exposed to a variety of vocabulary, fixed and idiomatic expression in translation tasks. Also, they must be aware of the cultural differences in translation idioms. The study further recommends that deploying fixed and idiomatic expressions in schools' and colleges' aisles could benefit the students in translation.
\end{abstract}

Keywords: Investigating, Problems, Challenges, Idioms, Source Language \& Target Language, Translation, equivalent

\section{INTRODUCTION}

English as a foreign language enhances one's opportunities to get a job in government, business, medicine, law, technology, military, industry and marketing. The translation is considered to be important in communicating and conveying the meaning of a sourcelanguage text (SL) by means of an equivalent target language (TL).
Nida (1964), asserted that in order to achieve an equivalent response, the translation should make sense; convey the spirit and the manner of the original; have the natural and easy form of expressions. Nida (1964) suggested two main types of equivalence; 1- Formal equivalence, and 2Dynamic equivalence. 
Ghazala (2008), claims an idiom is a phrase or an expression that has a figurative meaning or non-literal meaning. Idioms evolve the language; they are the building blocks of a language and civilization. They also have great intensity to make a language interesting and dynamic. Moreover, Idioms bring a spectacular illustration to everyday speech.

Gibbs Jr, R. W. (1986), Researched skating on thin ice: Literal meaning and understanding idioms in conversation, he found that people process idiomatic expressions and cannot be attributed to some idiosyncratic aspect of the procedure. This result suggests that people do not ordinarily process the complete literal or compositional interpretations of idioms. In addition, the result confirms the idea that people are automatically biased toward interpreting idiomatic expressions literally, before deriving their intended literal meanings.

Most students perceived that translation is an important method to convey the intended meaning from source language to target language, and it is an urgent need of delivering English culture through interpretation of the idiomatic expressions. However, EFL students feel wholly incapable of the ongoing translating idioms.

Idiomatic expressions are considered as one of the toughest, and yet the most interesting component of any language's vocabulary. This toughness is greatly influenced by their peculiar nature and being culturally bound. Based on these characteristics, Saudi EFL undergraduates encounter challenges in translating idiomatic expressions from English into Arabic and vice versa. This study discusses these problems and challenges in terms of their toughness and strategies employed in translating idioms.

EFL learners encountered mental distraction because they think on equivalence words more than the intended meaning of the sentence, and there is a lack of exposure to English idioms and translating skills at pre-university. The problems of translating idioms literally may be the barrier to successful translating competence for EFL students.

There's a problem which seems to confuse EFL learners in translating idioms and problems from English to Arabic, vice versa. Undergraduate students often complain about the difficulties involved in translating idioms expressions such as to 
fall in love, to be over the moon, or to be under the weather.

Some students when listening to a conversation or read a topic that contains idioms, they become frustrated. And some EFL learners when they unable to translate idioms into Arabic or vice versa are also frustrated. The difficulties might be due to a lack of knowledge concerning the exact meaning of idiomatic expressions. As a result, the students find themselves unable to translate the meaning of idiomatic expressions. In order to become better readers or listeners, they need to use a wide variety of idiomatic expressions.

The study aims to find out the factors that cause these challenges for Saudi EFL undergraduates in translating idioms from English into Arabic and vice versa. It also aims to explore the strategies that Saudi EFL undergraduates employ in translating idioms from English into Arabic and vice versa.

Due to the importance of translating idioms from English into Arabic and vice versa, The challenges can be formed in many ways. For example, the word "man" is used to form many idioms. The parts of the body are used to form numerous idioms. The names of various animals and various objects are also used to form idioms. Events and stories from theology, history, geography, science, mythology, legend, romance, economics, linguistics, medicine, law, politics, current events, sports, mathematics, biology, philosophy, and other subjects have been used in order to create this interesting branch of English. Therefore, the translators and interpreters have to know how to translate them properly to convey the intended senses or meaning.

Saudi Arabia has begun teaching the English language at the mids of the fifties of the last century. The beginnings were so slow. As known, English has taught as a foreign language at Saudi schools, colleges and universities.

More importantly, it increases their knowledge and awareness of translating idiomatic expressions and their culturebound nature to avoid poor translation of idioms. Moreover, this study presents an invaluable assist to teachers and translators in which it discusses and shows the challenges that EFL students face when translating these culture-specific phrases and sentences. Furthermore, it helps them to get remedies and employ new and creative methods for translation such as idioms expressions. Finally, it contributes to the solution of translation problems to not only Saudi EFL learners but also the 
ministry of higher education and curriculum developers and designers. Finally, this research is meant to add some

\section{REVIEW OF RELATED LITERATURES}

Idioms are linguistic expressions or lexical items. They represent objects, concepts or phenomena of material life to a given culture. They are urgent to any language in order to keep the local and cultural color of that language.

Green (1975), claimed that acquiring L2 idioms is remarkably difficult because each idiom is a fixed expression. Its linguistic elements form a unit, and they are arranged in a specific pattern, and the meaning is not derived merely from its individual components. However, most second-language learners have a strong desire to master L2 idioms in order to sound natural language.

Lattey (1986) claims that idioms are divided into two types: lexemic idioms and phraseological idioms. Lexemic idioms are lexical items that convey metaphoric meanings, such as the verbs in 'She broke his heart, and he broke his word.' Latter on, Lattey (1986: 220) notes that lexemic idioms can occur in several different parts of speech such as: Verb: Turn -in ('go to bed'), Noun: hot dog ('frankfurter'), up-to-date findings to English language translation

Adjective: black - and-white (' clearly one thing or the other e.g., good or bad'), Adverb: like a bird (said of eating, 'very little'), and hand in glove ('very close or friendly' often with negative intent toward hird parties').

On the other hand, phraseological idioms are contained in several parts of speech. The combination of several parts of speech allows a phraseological idiom to be more flexible than a lexemic idiom. Phraseological idioms are important in second language acquisition. They may not occur as often as many other parts of the language, but they exist crosslinguistically. For instance, the phraseological idiom 'The/An apple doesn't fall far from the tree' includes at least three parts of speech. For example, noun phrase (the apple), verb phrase (doesn't fall), adverbial phrase (far from the tree). The combination of parts of speech allows varying alternative forms, including, Mieder (1995: 11)

An apple never falls far from the tree, apples don't fall far from trees, 
The apple doesn't roll too

far from the tree, The

apple don't fall far from

the tree, the old apple

doesn't fall far from the

tree.

Bradshaw (1997) states that idioms or figures of speech are combinations of words whose meaning cannot be determined by examination of words' the meanings that make it up. In other words, an idiom uses a number of words to represent a single object, person or concept. Unless you recognize when an idiom is being used you can easily understand the meaning of a text. Modern translations, such as the NIV, use equivalent figures of speech in English to translate many biblical idioms. More literal versions, translate idioms word for word. It is the reader of the literal versions who need to be most aware of the meanings of figures of language.

Haegeman and Gueron (1999), shows that idioms are sentences containing idiomatic elements. According to them: "in a sentence containing an idiomatic element, the interpretation of the sentence is fully determined by the interpretation of its parts. For example, the idiom 'kick the bucket' has no apparent reason for meaning' 'die'. Thus, the effect of movement operations on idioms chunks is also not predictable.

Therefore, once the students are introduced to a new idiom, they may not be certain in which ways it can be used. To be fluent, they need elaboration with additional examples of acceptable usage and discrepant usage. This will require significant additional study time per idiom for the student, and preparation by the instructor. However, there is a lack of documentation about idioms and how they work. Total fluency with every idiom is not worth the amount of study time. Students need to be aware that idioms can change in form.

Ghazala (2008), claims that an idiom is a fixed phrase whose form is usually unchangeable, and whose meaning is always the same, inflexible, metaphorical and indirect. For example, 'hard task' can be translated directly; whereas, 'tall order' cannot because it should not be translated directly the fact that it's fixed and has indirect meaning. Therefore, the former is not an idiom whereas the latter is. One of the biggest problem in English as a Foreign Language is that the dilemma of prepositions and adverbs which come with the verbs. Phrasal verbs are well- 
established and extremely popular idioms. A phrasal verb is a combination of a verb+adverb/preposition, or both an adverb and a preposition (such as: "up, down, on, off, in, out, over, etc".). It has a special idiomatic meaning that cannot be understood from the individual meaning of the verb and the adverb/preposition taken together. The students are always confused about using prepositions in making phrases. The phrasal expression sometimes gives the literal meaning as in take out the garbage. However, most times, it gives us non-literal meaning as in the looking back on. An EFL student who loves English is confused using prepositions. The student reads: "I always knew looking back on my tears, would bring me laughter, but I never looking back on my laughter would make me cry".

Ghazala (2008: 138) suggests solutions in translating and understanding English proverbs which will be discussed in details through the following three main groups such as absolute equivalence, similar equivalence and different equivalence.

First, the absolute equivalence like 'like father like son'; 'like daughter like mother'; 'Don't put your duty still tomorrow'; 'There is nothing new under the sun'; 'All that glitters is not gold';
"Drowning man will clutch at a straw"; "Man is known by the company he keeps"; "What you sow, you will reap"; "I hear wheeling without milling"; "necessity is the mother of invention"...etc. The examples of this group are the easiest for the students to translate and understand because most of them can be translated and understood directly. However, the problem remains for the students to know the full form of proverb in Arabic more than in English. Furthermore, the solution is not hard to attain in any way, for they are usually fascinated by proverbs in both languages, and know some of them beforehand. With the help of authority and consultation of a specialist, references are available now.

The second kind of proverb division is the similar equivalence. The following examples are going to prove that division. The students understand the proverbs literally like "forbidden fruit is sweet"; "Blood is thicker than water"; "A bird in hand is worth two in a bush"; "Birds of the same feather flock together"; "Two minds are better than one"; "To make a dome out of a mole hill"; "A friend in need is a friend indeed"; "Better to be safe than sorry"; "Diamond cuts diamond"; "familiarity breeds contempt"; "when there is life there is hope"; "Charity begins at home"; "poverty no sin" and "let bygones be 
bygones". The proverbs of this group are harder to translate or understand than those of the first one. Yet, this does not mean that they are difficult to understand. Presumably, the knowledgeable apart of the proverb in Arabic is enough for the students to guess it in full.

Ghazala (2008), mentions that in discussing the translation of English idioms into Arabic, it can be traced through the following three groups, e.g., a) direct idioms, b) indirect idioms and, c) phrasal verbs.

The direct idioms such as "passing the exam is not a bed of roses.", "A true friend does not stab in the back.", "you scratch my back and I scratch yours.", and "He killed his neighbor in cold blood." Notably, these idioms are translated directly, but should be understood indirectly and have metaphorical meanings. Therefore, they are all fixed metaphorical expressions, saying something to mean something else. In order to illustrate this further, the followings intend direct meanings of the previous examples: "passing the exam is difficult.", "a true friend does not betray.", "serve me so that I serve you.", and "he killed his neighbor intentionally and insensitively."
The aforementioned expressions are direct meaning of the idioms under discussion. However, the students need to focus on meaning, not explaining English idioms into Arabic equivalent. Thus, students rely on the literal meaning of these idioms. However, when such meaning is not understood, it is funny or quite strange. They should realize that literal meaning is useless, as the idioms of group 'B' prove.

Ghazala (2008), names group 'B' as indirect idioms such as "My car is second hand.", "How nice to remember our palmy days.", "My niece is so selfish. She is a dog in the manger.", Beating the Brazilian football team is tall order.", "He is a big shot(gun)", "let us talk shop.", "There is a black sheep in every family.", "It's a donkey work to write a book.", and "He can walk on water." The examples of this group are quite a headache for students because they are entirely indirect and cannot be understood from the literal, common meaning of the words. The problem is clear to the students when these idioms are translated literally and indirectly.

Suchanova, J. (2013), conducted a research on the analysis of English and Lithuanian idioms and the problems of their translation. He found that there are many difficulties to non-native speakers when translating idioms due to the influence of 
traditions, culture, the environment and other factors on the form and contexts of the idioms. He revealed that any

\section{METHODS}

The population of this study is Saudi undergraduate students majoring in English at Onaizah Colleges, Qassim, Saudi Arabia. The sample was 20 EFL students. Subjects who participated in this study were drawn from different cultural background at Onaizah Colleges. They are all third and fourth university students and they studied at the English departments. Their ages vary from (20) and (21) years and they come from different areas in Saudi Arabia.

\section{RESULTS AND DISCUSSION}

The researcher presented the results of the questionnaire and explained the statistical significant differences between variables on percentages for all variables of the considered language is also shown speaker's insight which helps himlher to avoid some typical error.

A questionnaire with some modifications is designed to meet the objectives of the study. The purpose of these modifications is to make the questionnaire more applicable to the Saudi EFL environment. Questionnaire consists of ten statements regarding problems and challenges encountered by EFL students in translating idioms from Arabic into English, vice versa.

questionnaire. The researcher placed the results and added some comments and discussions with setting the graphical diagrams as explained herein: 


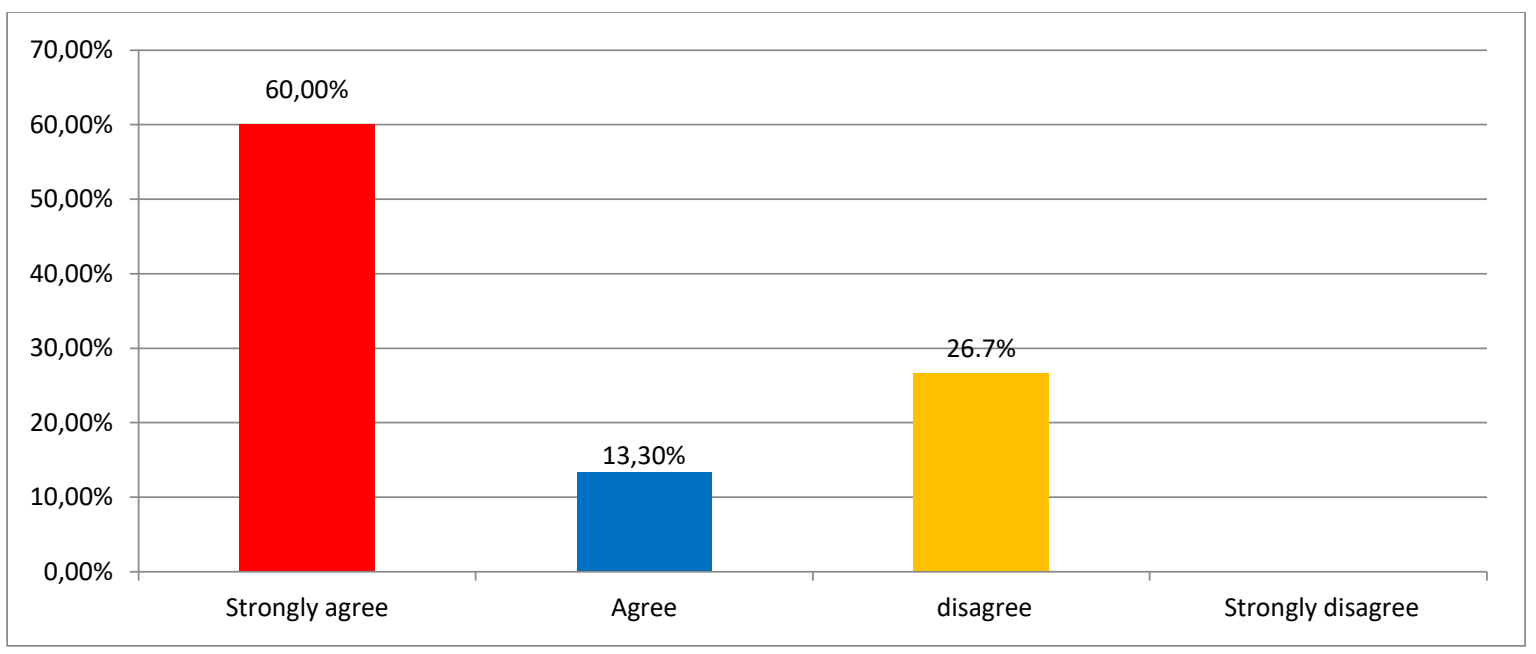

Figure 1. Problematic area of translating idioms for Saudi EFL students.

Results of the survey showed that questionnaire statement number (1) which is "translating idioms are a problematic area for Saudi EFL students."The significant difference between participants' results in variable (1) on questionnaire. Strongly agree recorded the highest percentage which is 60.0\% followed by Agree which 13.3\% whereas there is only $27 \%$ of students disagree that translating idioms are a problematic area for Saudi EFL students. Therefore, the significant difference in favor of agree that translating idioms are a problematic area for Saudi EFL students due to the high of the percentage of students' consensus which is $73.3 \%$. Thus, this result is considered that translating idioms are a problematic area for Saudi EFL students.

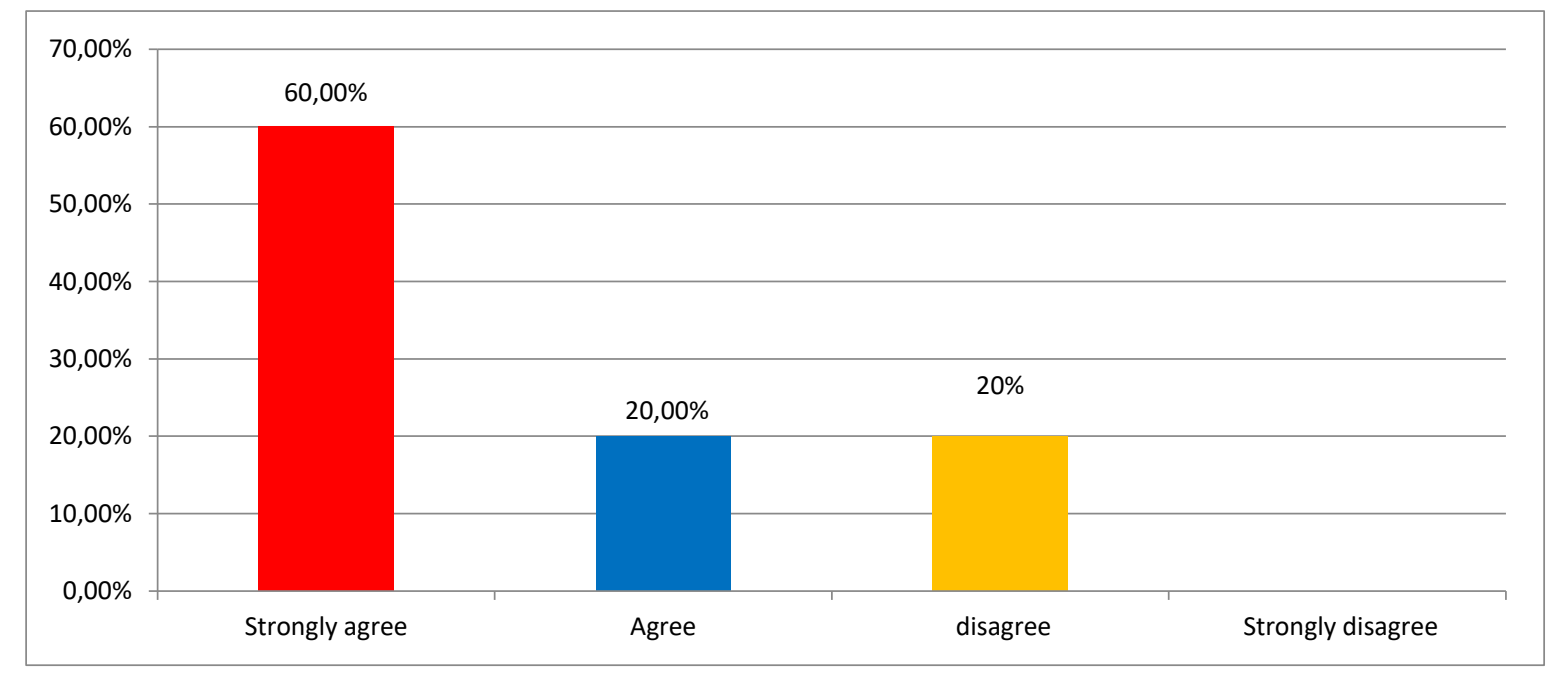

Figure 2. Difficulties in translating idioms into Arabic and vice versa due to the poor vocabulary

JEE (Journal of English Education) Vol. 7 No. 1. June 2021

http://journal.upp.ac.id/index.php/JEE

P-ISSN:2459-9719, E-ISSN 2597-7091

DOL: https://doi.org/10.30606/jee 
Based on statistics, questionnaire statement number 2, i.e., Saudi EFL students face some difficulties in Translating idioms from English to Arabic and vice versa due to the poor vocabulary. The result revealed that there is a significant difference between participants' results in variable (2) on questionnaire. The result demonstrates that there is highest percentage for strongly agree which is $60 \%$ and $20 \%$ for agree whereas the result shows lowest percentage or disagree which is $20 \%$. Therefore, $80 \%$ of the students' consensus agree that Saudi EFL students face some difficulties in Translating idioms from English to Arabic and vice versa due to the poor vocabulary. Therefore, this consensus supports Saudi EFL students face some difficulties in translating idioms from English to Arabic and vice versa due to the poor vocabulary.

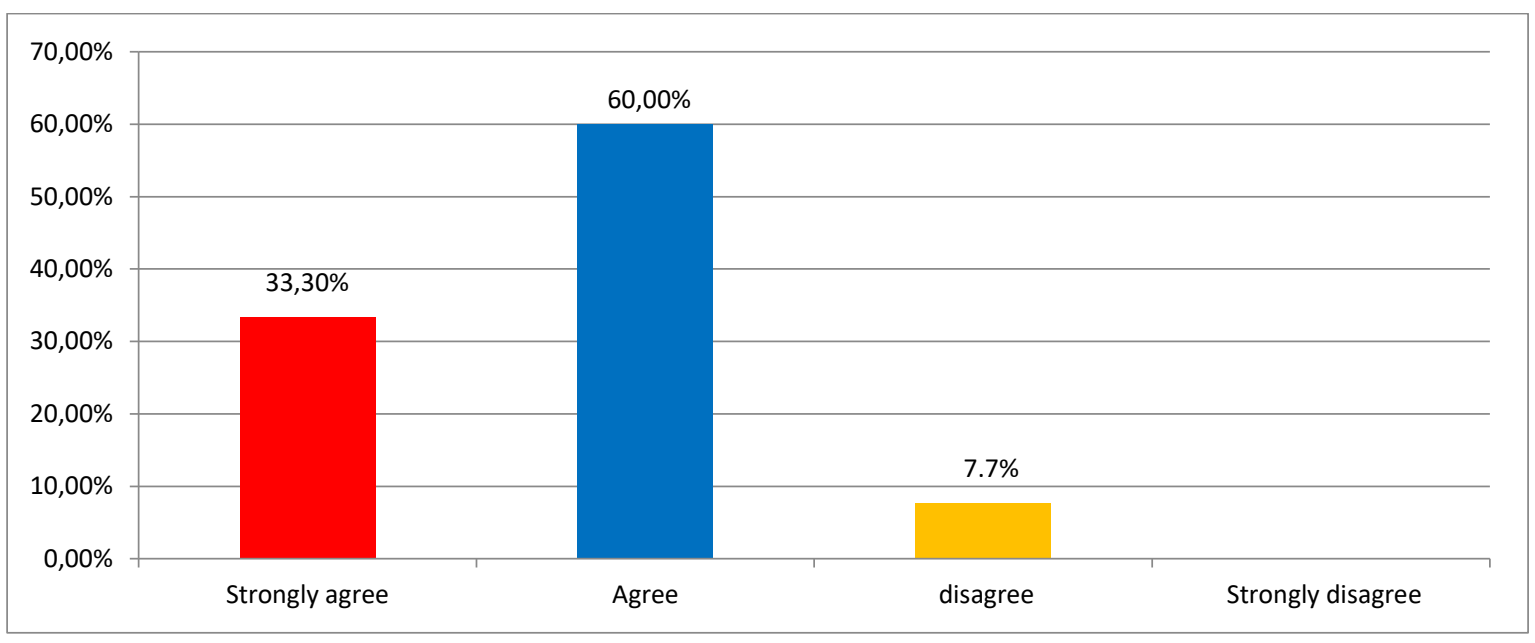

Figure 3. Importance of English Language culture in translating idioms into Arabic

The study revealed that there is a significant difference between participants' results in variable (3) on questionnaire, statement number 3, i.e., it is very important to know English language culture in order to translate idioms into Arabic language properly. The result showed that there is a high percentage for agree which is $60 \%$, and disagree agree which is $33.3 \%$. Therefore, the total percentage of students' consensus which is $93.8 \%$ indicates statistically the significant difference in favor of it is very important to know English Language culture in 
order to translate idioms into Arabic

Language properly.

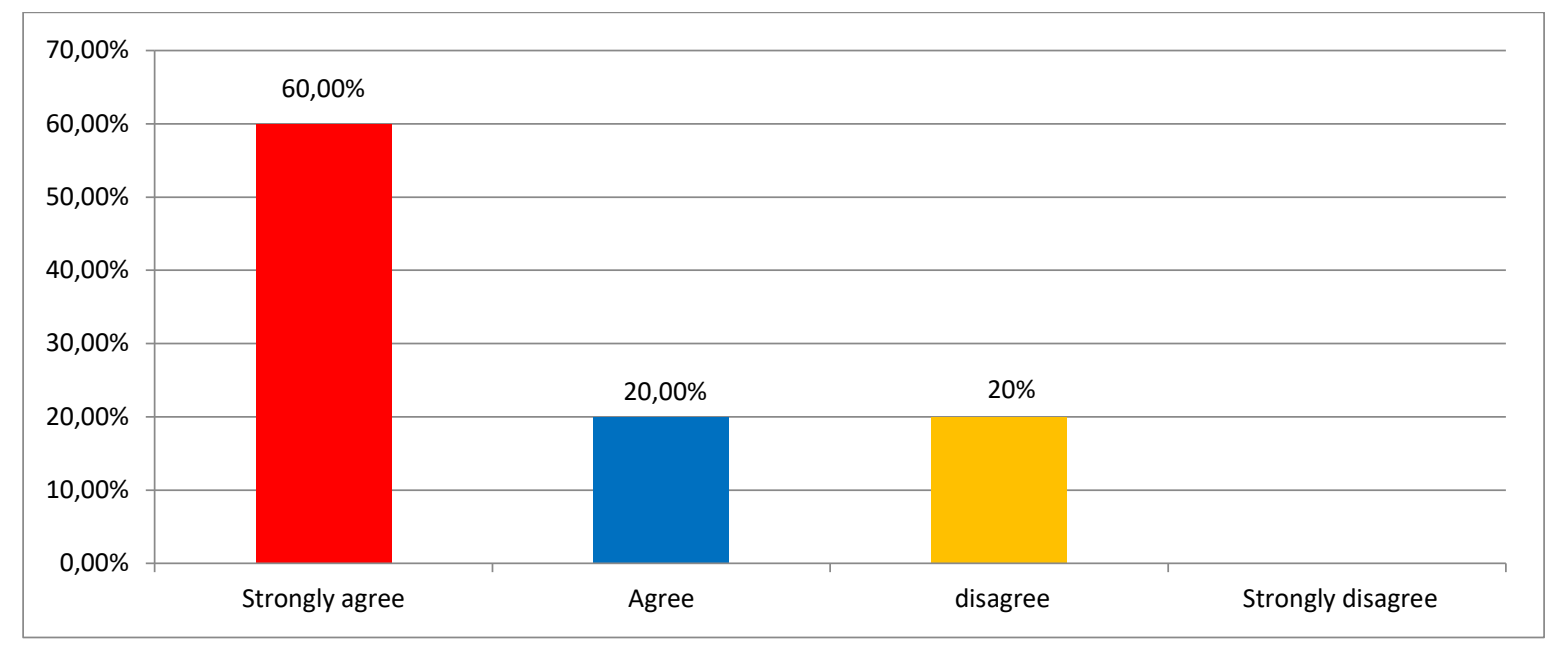

Figure 4. Lack of translating idioms from English into Arabic in pre-university

There is a significant difference between participants' results in variable (4) on questionnaire, Statement No. 4 which is what the students learned in preuniversity stages does not enable them to translate idioms from English to Arabic or vice versa correctly. Result showed that strongly agree has the highest percentage which is $60 \%$ and followed by agree which is $20 \%$. Therefore, the percentage of $80 \%$ indicates statistically the significant difference in favor of agree that what the students learned in preuniversity stages does not enable them to translate idioms from English to Arabic correctly. Thus, students need to study idioms from pre-university stages to enable them to translate idioms from English to Arabic correctly at university level.

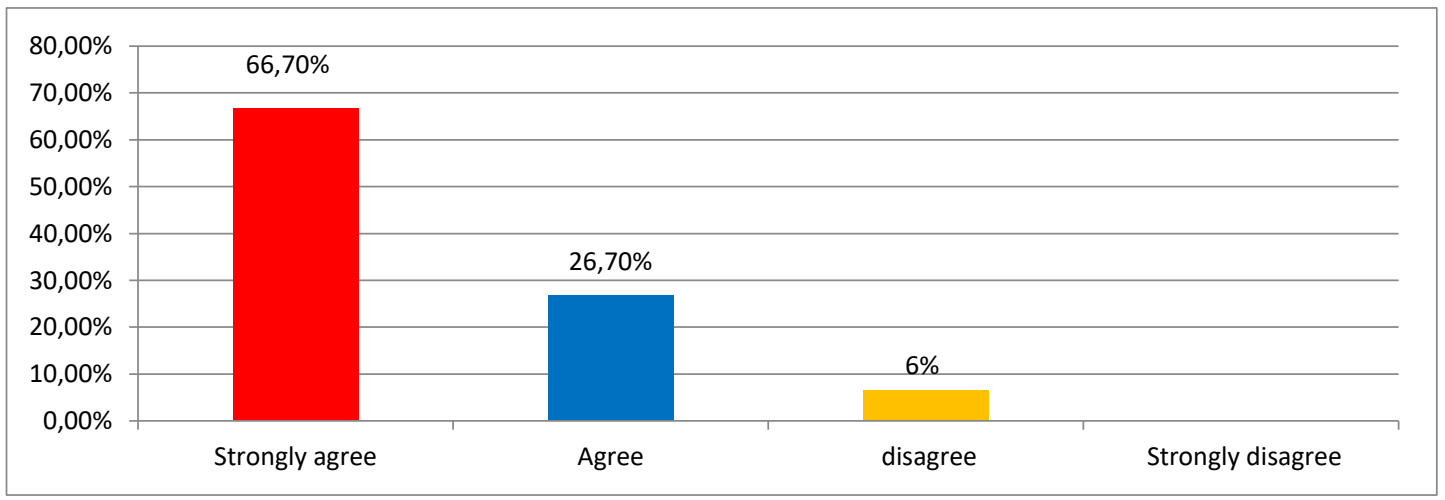

JEE (Journal of English Education) Vol. 7 No. 1. June 2021 
Figure 5. Starting translating idioms from elementary up to university level

Based on statistics, Questionnaire strongly agree which is $66.7 \%$ and $26.7 \%$ statement number 5, i.e., Idioms translation should be a part of English syllabi starting from elementary up to university level, the study revealed that there is a significant difference between participants' results in variable (5) on questionnaire. The result demonstrates that there is highest percentage for for agree whereas $6.4 \%$ for disagree. Therefore, $93.4 \%$ of the students' consensus agree that idioms translation should be a part of English syllabi starting from elementary up to university level. This consensus supports the difficulty of translating idioms into Arabic and vice versa.

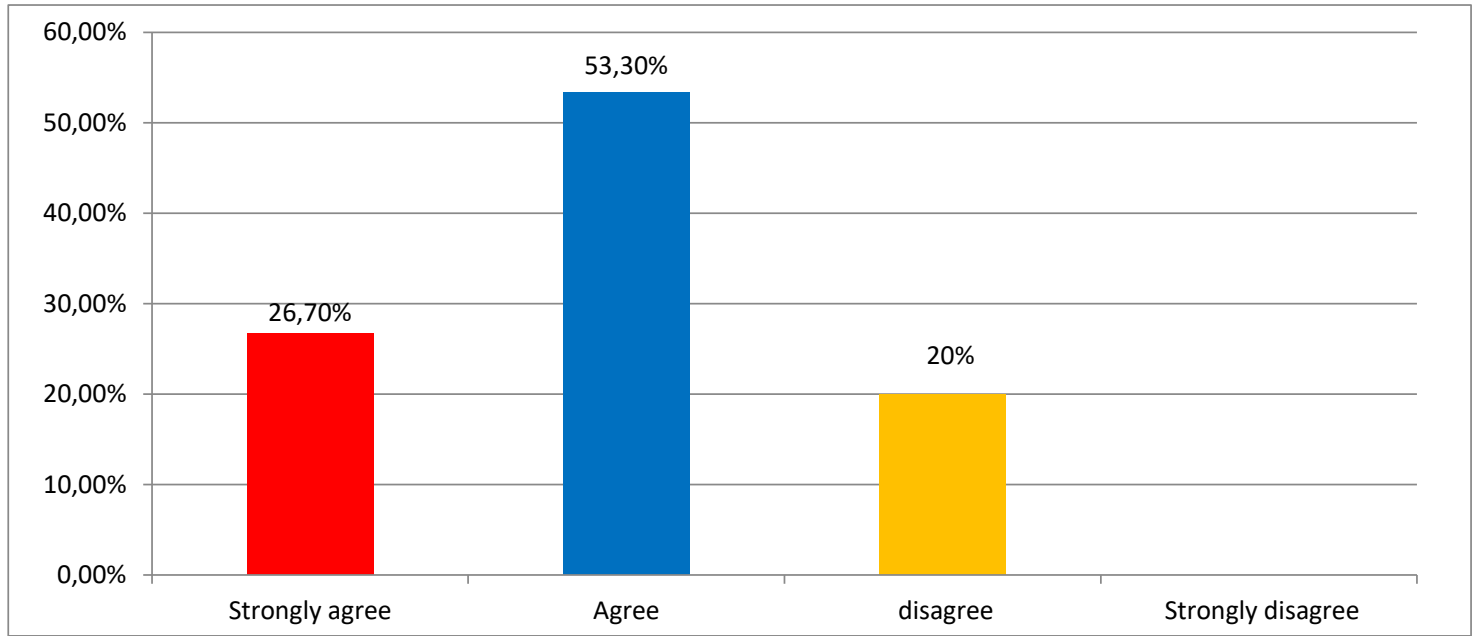

Figure 6. Confusion of translating idioms from English to Arabic and vice versa.

Saudi EFL students are confused in translating idioms from English to Arabic and vice versa which is Questionnaire Statement No. (6) has a high significant difference between participants' results in variable (6) on Questionnaire. Survey results revealed that $53.3 \%$ is recorded for agree, $26.7 \%$ for strongly agree, and $20 \%$ for disagree. Thus, $80 \%$ of Saudi EFL students are confused in translating idioms from English to Arabic and vice versa which lead to difficulty of translating idioms from English into Arabic. 


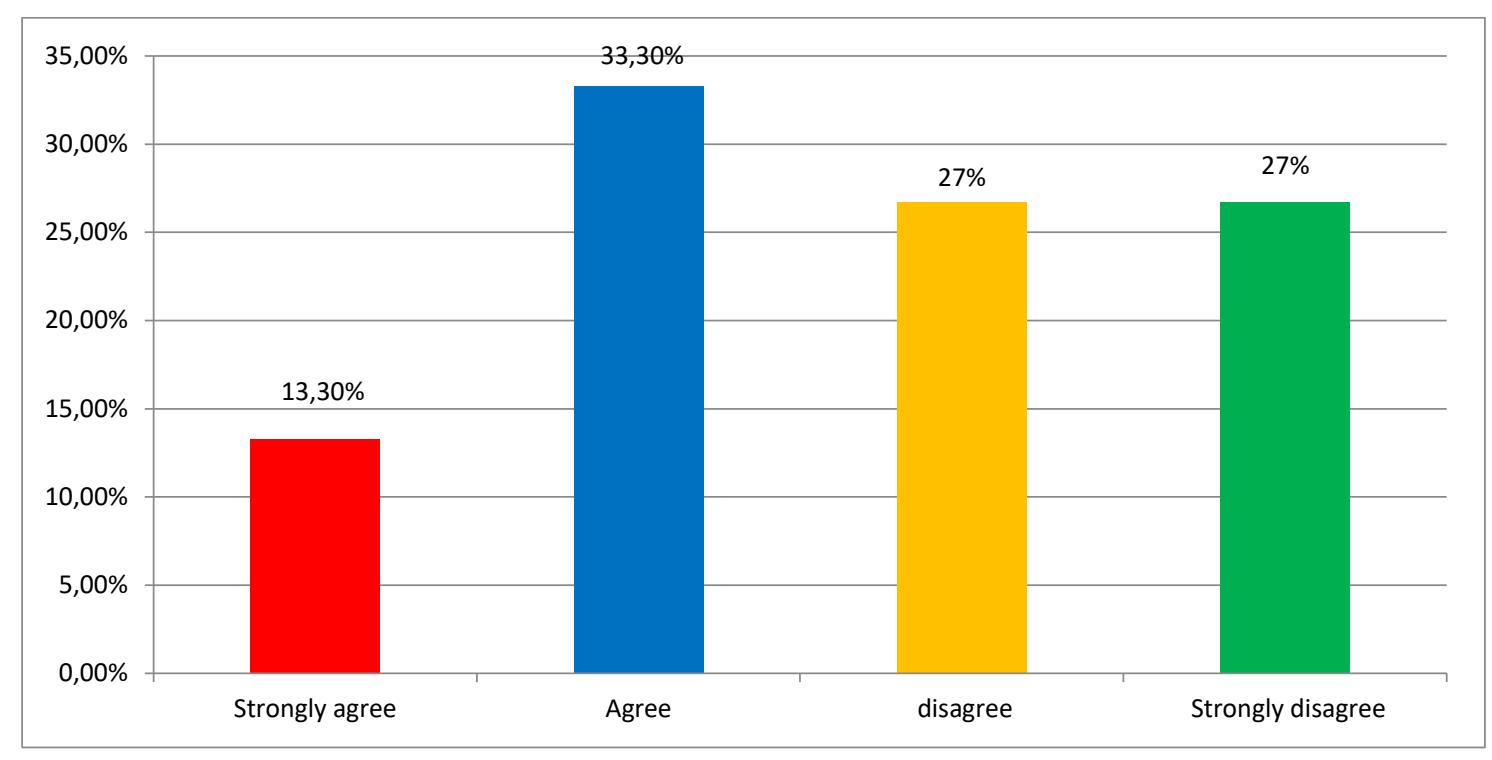

Figure 7. Encouraging EFL students to translate idioms into Arabic or vice versa.

Saudi English teachers do not encourage their students to translate idioms into Arabic or vice versa, which is Questionnaire Statement No. (7) has a high significant difference between participants' results in variable (7) on Questionnaire. Survey results revealed that $33.3 \%$ is recorded for agree and
13.3.6\% for strongly agree whereas the results demonstrated that $27 \%$ for disagree and $27 \%$ for strongly disagree. Thus, $54 \%$ of university students' consensus disagree that Saudi English teachers do not encourage their students to translate idioms into Arabic or vice versa. 


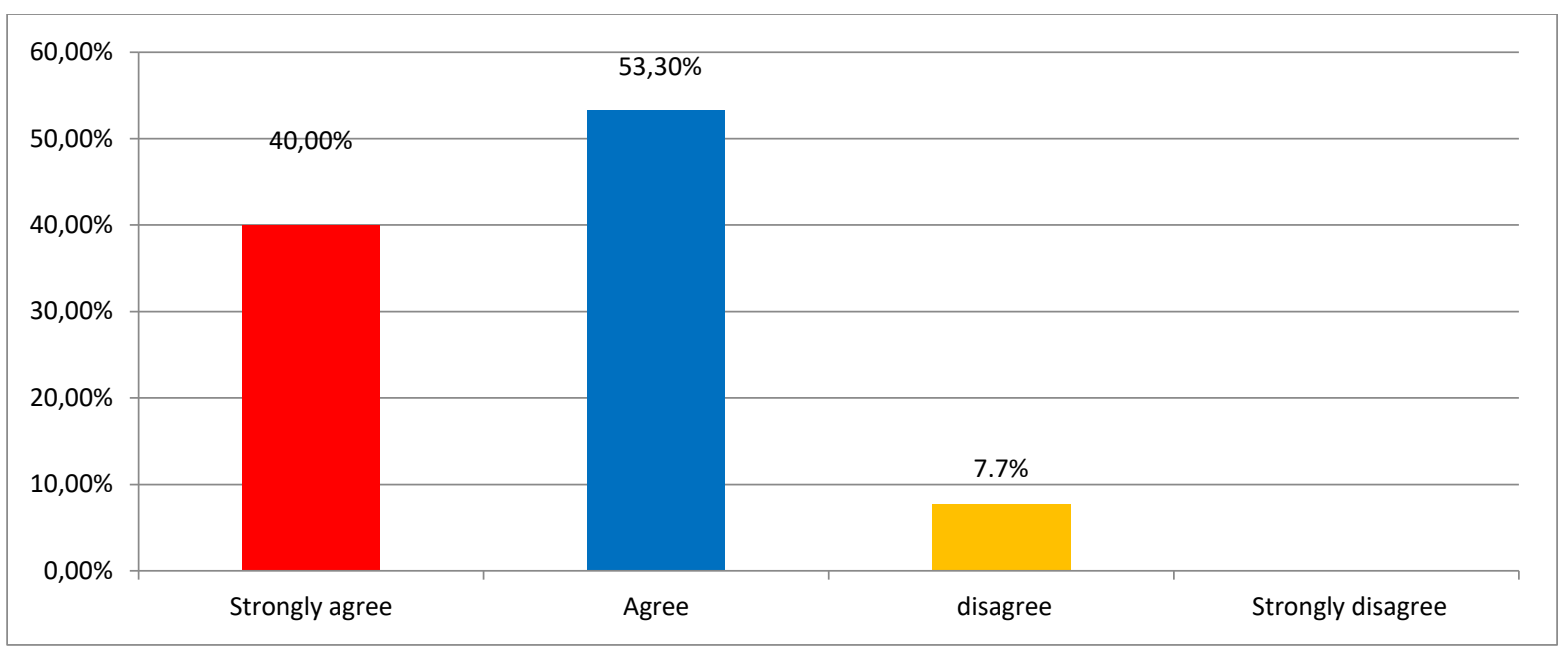

Figure 8. Giving enough Emphasis for translating idioms into Arabic.

Results of the survey showed that questionnaire statement number (8) which is Saudi Educators and syllabus designers do not give enough emphasis in translating idioms into Arabic." The significant difference between participants' results in variable No. 8 on questionnaire. Agree recorded the highest percentage which is $53.3 .7 \%$ and
$40 \%$ for strongly agree. Therefore, the significant difference in favor of agree that Saudi Educators and syllabus designers do not give enough emphasis in translating idioms into Arabic due to the high of the percentages. Thus, Saudi Educators and syllabus designers do not give enough emphasis in translating idioms into Arabic or vice versa.

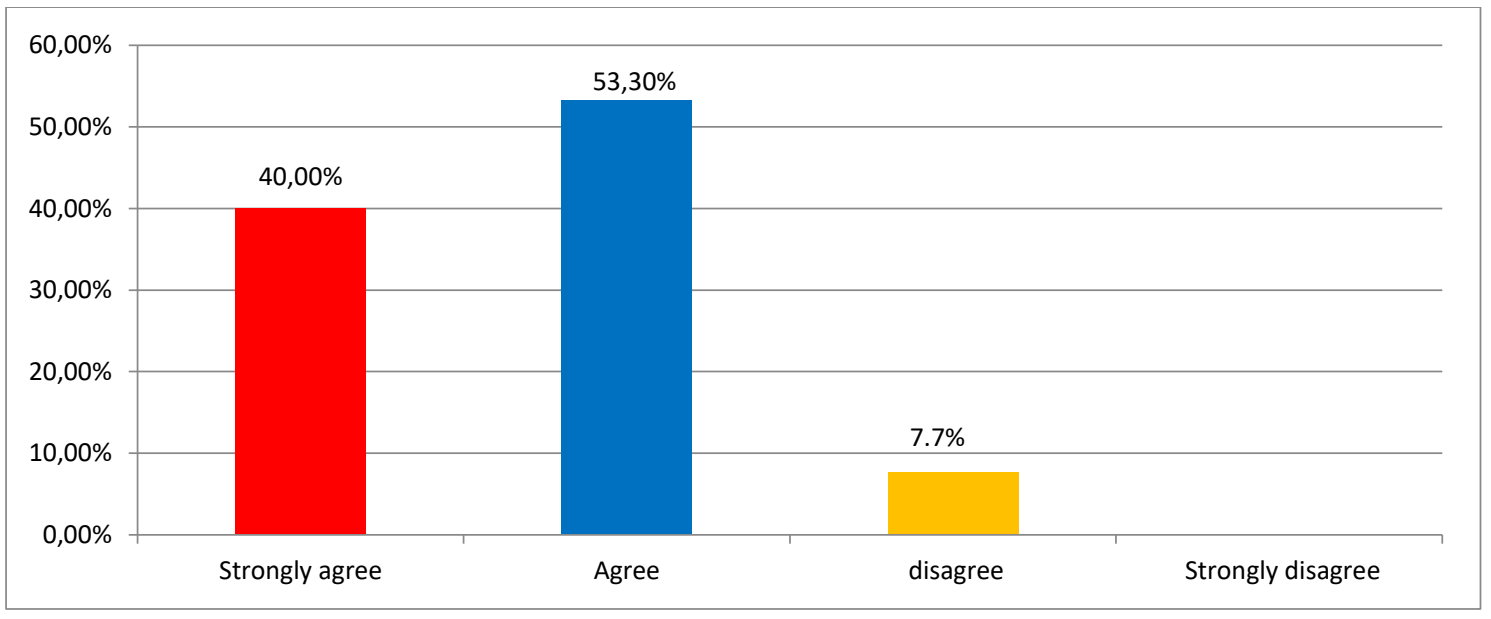

Figure 9. Translating the idioms from English to Arabic and vice versa literally

JEE (Journal of English Education) Vol. 7 No. 1. June 2021

http://journal.upp.ac.id/index.php/JEE

P-ISSN:2459-9719, E-ISSN 2597-7091

DOL: https://doi.org/10.30606/jee 
Based on statistics, Questionnaire statement number No. 9, i.e., Saudi EFL students translate literally the idioms from English to Arabic and vice versa, revealed that there is a significant difference between participants' results in variable (9) on questionnaire. The result demonstrated that there is highest percentage for agree and strongly agree which are $93.3 \%$, whereas $7.7 \%$ for disagree. Therefore, $93.3 \%$ of the students' consensus agree that Saudi EFL students translate literally the idioms from English to Arabic and vice versa. Therefore, EFL students translate the idioms from English to Arabic and vice versa literally as the words mention without think of intended meaning.

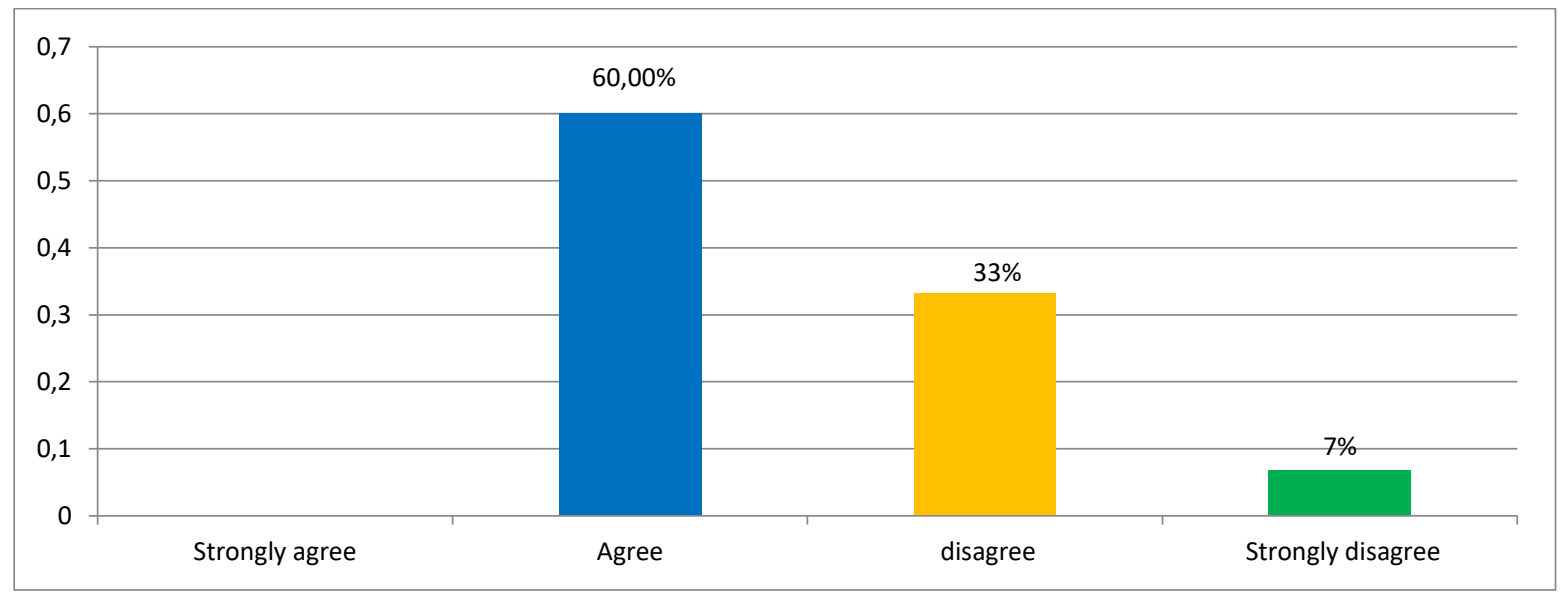

Figure 10. Lack of translating idioms from English to Arabic in teachers' interaction with their students

Study revealed that there is a significant difference between participants' results in variable (10) on questionnaire, Statement Number 10, i.e., University teachers do not translate idioms from English to Arabic in their interaction with university students. The result showed that a high percentage for agree which is $60 \%$, whereas a low percentage for strongly disagree and disagree which are $40 \%$.
This indicates statistically the significant difference in favor of agree that university teachers do not translate idioms from English to Arabic in their interaction with university students.

Referring to the questionnaire, which investigated the problems encountered by EFL students in translating idioms from Arabic into English and vice versa at 
Onaizah Colleges, K.S.A. The subjects' responses of this study as follow:

1- Translating idioms are a problematic area for Saudi EFL students.

2- Saudi EFL students face some problems in translating idioms from English to Arabic and vice versa due to the poor vocabulary.

3- It is very important to know English Language culture in order to translate idioms into Arabic Language properly.

4- What the students learned in preuniversity stages does not enable them to translate idioms from English to Arabic or vice versa correctly.

5- Idioms translation should be a part of English syllabi starting from elementary up to university level.

6- Saudi EFL students are confused in translating idioms from English to Arabic and vice versa.

7- Saudi English teachers do not encourage their students to translate idioms into Arabic or vice versa.

8- Saudi Educators and syllabus designers do not give enough emphasis in translating idioms into Arabic."

9- Saudi EFL students translate the idioms from English to Arabic and vice versa literally.
10- University teachers do not translate idioms from English to Arabic in their interaction with university students

According to the findings of the study, the researcher recommends the

\section{following:}

1) Saudi EFL students should expose to various translation of idiomatic expressions in order to avoid mistranslation of idioms from English to Arabic or vice versa.

2) EFL students should expose to vocabulary, fixed phrases and idioms in order to resolve the problems of translating idioms from English to Arabic and vice versa due to the poor vocabulary.

3) EFL students should expose to English Language culture in order to help them translating idioms into Arabic Language easily and properly.

4) EFL students should learn how to to translate idioms from English to Arabic correctly from early stages or preuniversity stages to enable them translating easily and correctly.

5) Idioms translation should be a part of English syllabi starting from elementary up to university level to strengthen the EFL students when 
translating English idioms into Arabic or vice versa.

6) Saudi EFL students should expose to English idioms to avoid the confusion of translating idioms from English to Arabic and vice versa.

7) Saudi English teachers should continue encouraging EFL students to translate idioms into Arabic or vice versa.

\section{DISCUSSION}

The preceding analysis suggests some of the problems encountered by EFL students in translating idioms from Arabic into English and vice versa at Onaizah Colleges, K.S.A. The EFL students did not seem to have much opportunity to deal with translating idioms due to lack of vocabulary, fixed expressions, idiomatic expressions and English culture. Various reasons were noted, such as the students did not expose to idioms before translating idioms from English into Arabic or vice versa. Therefore, there were a lot of hindrances which were the result of poor vocabulary and idiomatic phrases were factors that impede them to translate the idioms into Arabic or vice versa.

The main difficulties that faced EFL students in translating idioms into Arabic or vice versa are 1) the difficulties
8) Saudi Educators and syllabus designers should give enough emphasis in translating idioms into Arabic.

9) Saudi EFL students should not translate the idioms from English to Arabic and vice versa literally.

University teachers should translate idioms from English to Arabic in their interaction with university students.

in Translating idioms from English to Arabic and vice versa due to the poor vocabulary, and; 2) there is a lack of English Language culture which it does not help them translate idioms into the Arabic Language properly, and; 3) students did not learn how to translate idioms from English to Arabic correctly from early stages or pre-university stages to enable them translating easily and correctly, and; 4) Idioms translation was not a part of English syllabi starting from elementary up to university level to strengthening them when translating English idioms into Arabic, and; 5) Saudi EFL students do not expose to English idioms to avoid the confusion of translating idioms from English to Arabic and vice versa, and 6) Saudi EFL students translate the idioms 
from English to Arabic and vice versa literally.

Most of the respondents pointed clearly to translating the idioms from English to Arabic and vice versa literally The respondents found it difficult to translate the intended meaning of the idiomatic expressions because they are not exposed to various types of translating idioms into Arabic or vice versa. Therefore, most of the students translate idioms and fixed expressions literally due to misunderstanding of idioms. They forget that idioms expressions are fixed phrases and they are more different than other expressions. Every individual student should expose to vary of idioms and translate them into Arabic and vice versa.

Lack of exposure to idioms expressions was a real problem that impeded mastery over English idioms translation. Most of the respondents believed that there is little vocabulary leads to misunderstanding and weakness of translating idioms into Arabic and vice versa. There was little awareness of the importance of translating idioms, most of the respondents agreed that Saudi EFL students face some difficulties in Translating idioms from English to Arabic and vice versa due to the poor vocabulary.
They do not give their best to recall or think critically while translating idioms into Arabic and vice versa.

According to the respondent's results, they pointed obviously that idioms translation should be a part of English syllabi starting from elementary up to university level where they will expose them to many idioms translation and enrich their vocabulary and culture. Thus, when they come to university, they will be familiar with the most common idiomatic expressions, and they will translate them effortlessly and properly.

Another problem that has faced Saudi EFL students in translating idioms from English to Arabic and vice versa is the confusion of idioms expression. Most of them do not know whether the sentence is idioms or not because they do not experience sentences like them before or because of vocabulary lacking. Therefore, they do not appropriately translate idioms.

Despite translating idioms are difficult tasks, and yet, Saudi EFL students show deep interest in translating idioms expressions into Arabica and vice versa. Most importantly, all the students showed awareness of the significance of translating idioms as a good way to understand native speakers culture and heritage which have contributed on convey the meaning of the 
English language in a precise and concise way.

\section{CONCLUSION}

Although most of Saudi EFL students at private colleges and universities understand the significance of fixed phrases and idiomatic expressions in communication; however, they still face difficulties in translating them properly. The findings of this study indicate obviously that translating idioms from English to Arabic or vice versa are a problematic area for EFL students at universities. Thus, these difficulties need serious and speedy treatment and solutions from EFL students, teachers, and lecturers, educators, and syllabi designers.

The faculty staff of English language should devout enough time to the EFL learners to practice translating idioms from
English into Arabic language and vice versa. They should draw great attention to translating idioms expressions. Lecturers and teachers should adopt a strategy for teaching idioms translation and work hard to raise EFL learners' translation through practicing various idioms translation tasks, and trying to catch up the latest English idioms expressions. In addition, they should encourage EFL learners to take part in the English contest and motivate them while translating idioms expressions. Therefore, the mentioned suggestions will contribute in solving the problems of idioms translation which are encountered by EFL students while translating idioms from English into Arabic or vice versa.

\section{REFERENCES}

Abdullah, K. and Jackson, H. (1998). Idioms and the language learner: Contrasting English and Syrian Arabic. Languages in Contrast, 1, 183-207.

Ackerman, B.P. (1982b). On Comprehending Idioms: Do children get the picture? Journal of Experimental Child Psychology, 33, 439-454.

Akbarian,G., Jones, A., \&West, G. (1992). young children's idiom comprehension:Trying to get the picture. Journal of Speech and Hearing Research, 35, 580-587. 
Alvarez, R. and Vidal, M. (1996). Translation, Power, Subversion (Multilingual Matters Ltd., Clevedon, Philadelphia).

Buhofer, H. \& Burger, H. (1994). Literal and Figurative Meanings of Idioms. About.com. (2013). Retrieved on 20 June 26, 2013

Cedar, P. (2008). Learners' Recognition of Thai-English Idiom Counterparts, Vol. 3. Issue 3, Naresuan University, Thailand. December 2008.

Cooper, T. C. (1999), Processing of Idioms by L2 Learners of English. TESOL-Quarterly 33/2, 33-262.

Drew, P. (1988). Complainable Matters: The use of Idiomatic Expressions in Making Complaints, vol. 35 .

Etela, Z. (2015). Complainable Matters: The use of Idiomatic Expressions in Theoretical Equilibrium, and Family Resemblance in Scientific Metaphors". Electronic Version, Philosophical Faculty, University of Eastern Finland.

Fernando, C. (1996). Idioms and Idiomaticity. Oxford: Oxford University Press.

Gentzler, E. (1993). Contemporary Translation Theories, London and York: Routledge, p. 53.

Ghazala, H. (1998). Translation as Problems and Solutions, Special edition, Dar El-ILM LILMALAYIN, (2008).

Gibbs Jr, R. W. (1986). Skating on thin ice: Literal meaning and understanding idioms in conversation. Discourse processes, 9 (1), 17-30.

Green, G. M. (1975). Nonsense and reference; or, the conversational use of proverbs.

In Chicago Linguistic Society (Vol. 11, pp. 226-39).

Irujo, S. (1993). Steering clear - Avoidance in the production of idioms. IRAL - International Review of Applied Linguistics in Language Teaching, 31(3), 205-219.

Irujo, S. (1986), A piece of cake: Learning and Teaching Idioms. English Language Teaching 40, 236-242.

Kerbel, D., and Grunwell, P. (1997), Idioms in the classroom: An investigation of language unit and mainstream teachers' use of idioms. Child Language Teaching and Therapy, 13,113-124.

Kiwan, A. (1987), The Dictionary of English and Arabic Proverbs. Beirut: Dar Al- Bihar, Dar wa Maktabat Al-Hilal, (2008).

JEE (Journal of English Education) Vol. 7 No. 1. June 2021

http://journal.upp.ac.id/index.php/JEE

P-ISSN:2459-9719, E-ISSN 2597-7091

DOL: https://doi.org/10.30606/iee 
Lattey, E. (1986). Pragmatic classification of idioms as an aid for the language learner. IRAL - International Review of Applied Linguistics, 24(3), 217-233

Laufer, B. (2000). Avoidance of idioms in a second language: The effect of L1-L2 degree of similarity. Studia Linguistica, 54(2), 186-196.

Mäntylä, K. (2004). Idioms and language users. The effect of the characteristics of idioms on their recognition and interpretation by native and non-native speakers of English. Jyväskylä Studies in Humanities, nro 13

Moon, R. (1998). Fixed expressions and idioms in English. Oxford: Oxford University Press.

Myers, I. and Briggs, K. (1956), "Briggs-Myers Type Indicator" Journal, New republic, 1944.

Newmark, P. (1988), A Textbook of Translation, (London: Prentice Hall).

Nida, E. A. (1964). Toward a Science of Translating. Leiden: Brill, p. 159.

Nippold, M.A.(1990), idioms in textbooks for kindergarten through eighth grade students. Unpublished manuscript. University of Oregon, Eugene.

Oxford (2002), Oxford Dictionary of Current Idiomatic English, (OUP).

Pulman, S. (1993). "The recognition and interpretation of idioms." in C. Cacciari and P. Tabossi (Eds.) Idioms: Processing, structure and interpretation. Hillsdale, NJ (\& Hove and London): Lawrence Erlbaum Associates, Publishers, 249-270.

Robinson, D. (1997), Becoming a Translator, (Routledge: London and New Yourk). Searle, J. R. (1993), "Metaphor." Metaphor and Thought, $2^{\text {nd }}$ ed., ed. by Andrew Ortony. Cambridge Univ. Press, (1993).

Snell-Hornby, M. (1988), Translation Studies: An Integrated Approach, (Benjamins Publishing Company: Amsterdam/Philadeliphia.

Strand, K.E., Fraser, B. (1979), The comprehension of verbal idioms by young children. Unpublished paper, School of Education, Boston University, Boston, MA.

Suchanova, J. (2013). The Analysis of English and Lithuanian Idioms and the Problems of Their Translation. Coactivity: Philology, Educology/Santalka: Filologija, Edukologija, 21(2), 154-161.

Thiel, F. (1979). The case for idioms. Die Unterrichtspraxis, 12, 21-24.

Turner, N. E., and Katz, A.N. (1997), Availability of conventional and of literal meaning during the comprehension of proverbs. Pragmatics and Cognition, 5, 199-233.

JEE (Journal of English Education) Vol. 7 No. 1. June 2021

http://journal.upp.ac.id/index.php/JEE

P-ISSN:2459-9719, E-ISSN 2597-7091

DOL: https://doi.org/10.30606/iee 


\section{(c) (i) (2)}

NonComercial-ShareAlike 4.0 International License.

JEE (Journal of English Education) Vol. 7 No. 1. June 2021

http://journal.upp.ac.id/index.php/JEE

P-ISSN:2459-9719, E-ISSN 2597-7091

DOL: https://doi.org/10.30606/iee 